\title{
Antibiotic prescriptions and laboratory-confirmed cases of Mycoplasma pneumoniae during the epidemic in Sweden in 2011
}

A Linde (Annika.Linde@smi.se) ${ }^{1}$, A Ternhag ${ }^{1}$, A Törner¹, B E Claesson²

1. Department of Analysis and Prevention, Swedish Institute for Communicable Disease Control, Sweden

2. Department of Clinical Microbiology, Unilabs AB, Kärnsjukhuset, Skövde, Sweden

Citation style for this article:

Linde A, Ternhag A, Törner A, Claesson BE. Antibiotic prescriptions and laboratory-confirmed cases of Mycoplasma pneumoniae during the epidemic in Sweden in Linde

Euro Surveill. 2012;17(6):pii=20082. Available online: http://www.eurosurveillance.org/ViewArticle.aspx?Articleld=20082

Article published on 9 February 2012

Swedish laboratories reported an increase of Mycoplasma pneumoniae during the autumn 2011. Data from the laboratory in Skövde, covering $12.9 \%$ of the Swedish population, indicate an approximate increase in the number of laboratory-confirmed cases in the whole country, from around 3,500 in 2009 to 11,100 in 2011. Antibiotics are recommended only for pneumonia, not bronchitis, but compared with the autumn 2009, 42,652 more prescriptions of doxycycline and macrolides were registered in the autumn 2011.

\section{Introduction}

Mycoplasma pneumoniae infections are not reportable in Sweden, but in the autumn 2010, the Swedish Institute for Communicable Disease Control (SMI) received informal information from several laboratories that the number of laboratory-confirmed diagnoses of M. pneumoniae had increased, and in 2011 an even greater increase was noted. However, reports from different laboratories were not comparable because information on methodology and/or total number of examined samples per population were missing.

The laboratory in Skövde covers $12.9 \%$ of the Swedish population. It has collected data from 2002 to 2011 on polymerase chain reaction (PCR) results and the total number of examined samples for bacteria causing protracted cough: M. pneumoniae, Chlamydophila pneumoniae and Bordetella pertussis/parapertussis. In addition, it has collected data on $M$. pneumoniae IgM serology since 2006. Sampling of these cough pathogens was performed only for clinical purposes and the number of collected samples thus reflect provisional diagnoses or suspicions of the clinical doctor. We use the data from Skövde as a proxy to analyse the epidemic in Sweden as a whole.

The risk of antibiotic resistance due to overuse of antimicrobial drugs and the negligible benefit of treating the mild symptoms caused by Mycoplasma [1] has prompted the Swedish strategic programme against antibiotic resistance (Strama) together with the Swedish Medical Product Agency [2], as well as other organisations in Europe [3], to issue strict recommendations for antibiotic treatment of Mycoplasma infections. The Strama recommendations have been described in three reports on Mycoplasma in the SMI weekly newsletter in 2010, 2011 and 2012 [4-6]. We therefore found it of interest to compare the increase in the use of penicillin $\mathrm{V}$, generally recommended for treatment of pneumonia, with that of doxycycline and macrolides, recommended for atypical pneumonia, in relation to the ongoing epidemic. Further, we wanted to analyse the relation between the number of $M$. pneumoniae-positive samples and the number of antibiotic prescriptions and compare this with data recently published from Finland, Norway and Denmark [7-9] and for Europe [3].

\section{Methods}

The microbiology laboratory at Kärnsjukhuset in Skövde (Unilabs AB) serves $1,225,000$ people in southern Sweden, which corresponds to $12.9 \%$ of the Swedish population.

Real-time PCRs were performed daily for M. pneumoniae, targeting a $76 \mathrm{bp}$ region of the adhesion gene [10], for $C$. pneumoniae, targeting a 78 bp region of the MOMP gene [11] and for $B$. pertussis and parapertussis, targeting a $154 \mathrm{bp}$ fragment of the IS481 gene and a $186 \mathrm{bp}$ fragment of the IS1001 gene, respectively [12]. Sampling for pathogens in the lower respiratory tract was usually performed with ESwabs (Copan) from the retropharyngeal wall. An IgM assay (Ani Labsystems) was also used on request.

The SMI has been collecting national data on monthly antibiotic prescriptions every third month since 2007, using a nationwide data base (Concise, Apoteket 
Service $A B$ ) covering all prescriptions from both outpatient and inpatient care. Data were aggregated to prescriptions per months.

\section{Results}

The number of samples examined by PCR for pathogens causing cough between 2002 and 2011 varied from 350 to 3,000 per year, with the highest level in 2011. The variation over time in the number of diagnoses and the positivity rate for each of the three agents is clear (Figure 1). The number of $M$. pneumoniae diagnoses increased from 2005 to 2007 and from 2010 to 2011, with peaks in 2006 and 2011 (Figure 2). In 2006 there were 341 PCR diagnoses of $M$. pneumoniae, and 585 in 2011 , but the detection rate was $23 \%$ both years (Figures 1 and 2).

Of an additional 3,882 samples tested serologically, 660 were positive for M. pneumoniae IgM in 2011, with a positivity rate of $17 \%$. If we allow a rough approximation for national comparisons, based on PCR and IgM results from Skövde, this corresponds to 117 confirmed diagnoses per 100,000 population in 2011 , a total of around 11,000 cases for the whole of Sweden.

The use of penicillin $\mathrm{V}$ and doxycycline/macrolides decreased slightly during the five-year period from 2007 to 2011 (Figure 3). Comparing the non-epidemic period July to December 2009 with the epidemic peiod July to December 2011 the number of penicillin $\checkmark$ prescriptions increased by approximately $9 \%$ (from 501,501 to 548,387 ). During the same time period the number of doxycycline and macrolide prescriptions increased by $25 \%$ (from 218,694 to 272,515 ).

\section{Discussion}

To create standardised surveillance systems for various infectious diseases and syndromes, like the sentintel system for influenza, is presently not feasible. Multiplex laboratory analyses of relevant agents for specified clinical conditions such as cough could be a substitute system for early warning and estimation of the impact of epidemics, if appropriate data are systematically reported and analysed. The PCR diagnostics in Skövde reveal changes over time in the spread of all four microbes monitored, and so far the outbreaks of Mycoplasma have given rise to the largest epidemics. Similar increases in laboratory-verified Mycoplasma during 2011 were reported from laboratories all over Sweden. While this rate estimation for the country of around 120 per 100,000 population is very approximate, it is similar to those reported from the other Nordic countries [7-9], indicating that the epidemics have been of similar magnitude across these countries. However, epidemic differences do occur, the outbreak in Denmark during 2010 for instance seemed more intense than in Sweden, and the previous epidemic peaked in 2005 in Finland and in 2006 in Sweden.

Even with IgM results included, the estimated positivity rate for $M$. pneumoniae was slightly lower in Sweden than that reported from Finland and Norway $[7,8]$. The lower rate could be due to less intensive

\section{FIGURE 1}

Number of samples tested for Mycoplasma pneumoniae, Chlamydophila pneumoniae and Bordetella pertussis/parapertussis and the rate of positives per half year, Skövde, 2002-2011

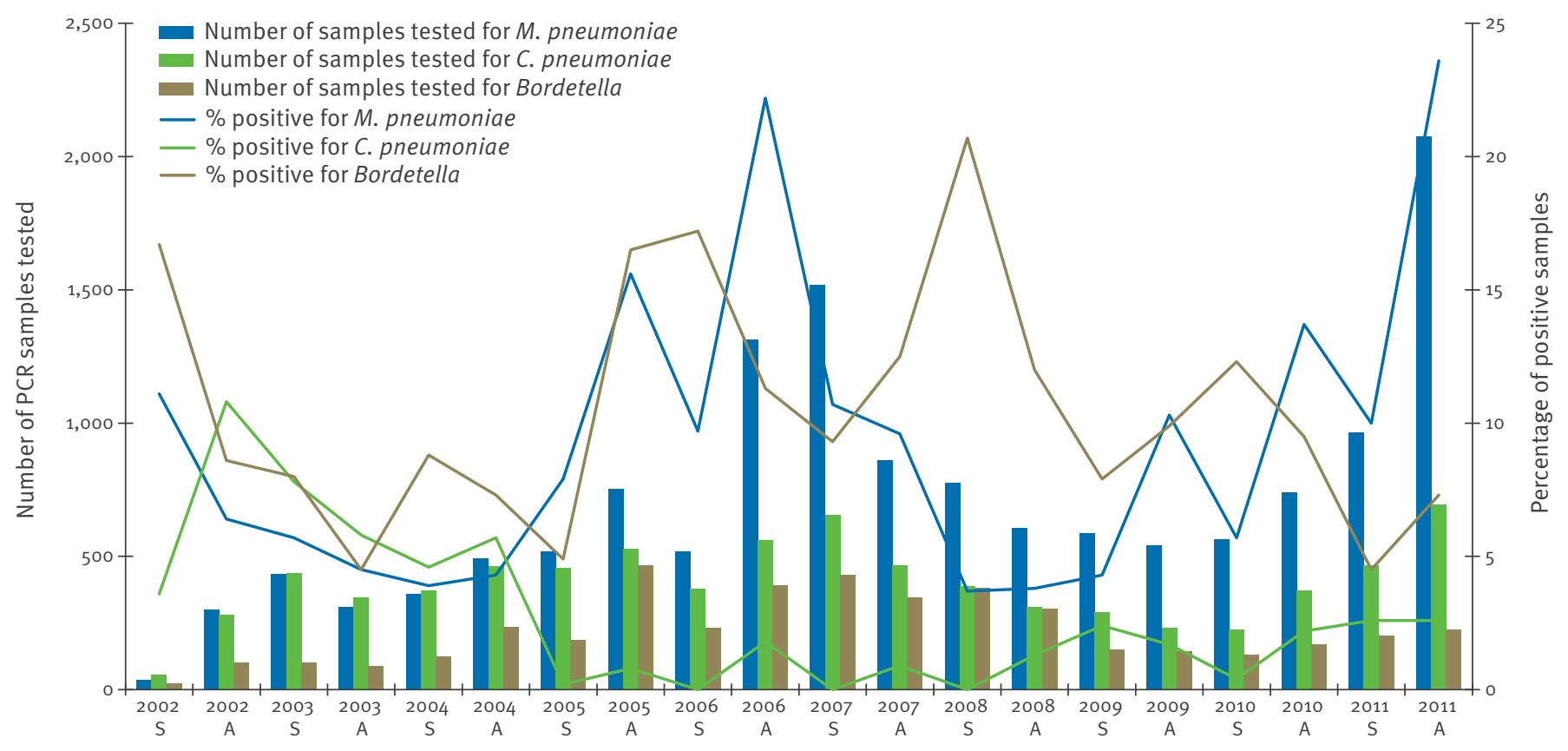

A: autumn; S: spring. 
epidemic spread, less sampling, variations in the methods used for diagnosis or a combination of these factors. The laboratory confirmation of Mycoplasma has until recently rested largely on serology, and still does in Finland [7]. The IgM assays, however, were lacking in sensitivity [13], and collection of paired samples for verification of the diagnosis is often not feasible. An excellent correlation between PCR for Mycoplasma and several commercial serology test systems has been shown [14], while only $30-40 \%$ of the patients had a positive IgM test at the first visit.

\section{FIGURE 2}

Number of samples positive for Mycoplasma pneumoniae, Chlamydophila pneumoniae and Bordetella pertussis/parapertussis per half year, Skövde, 2002-2011

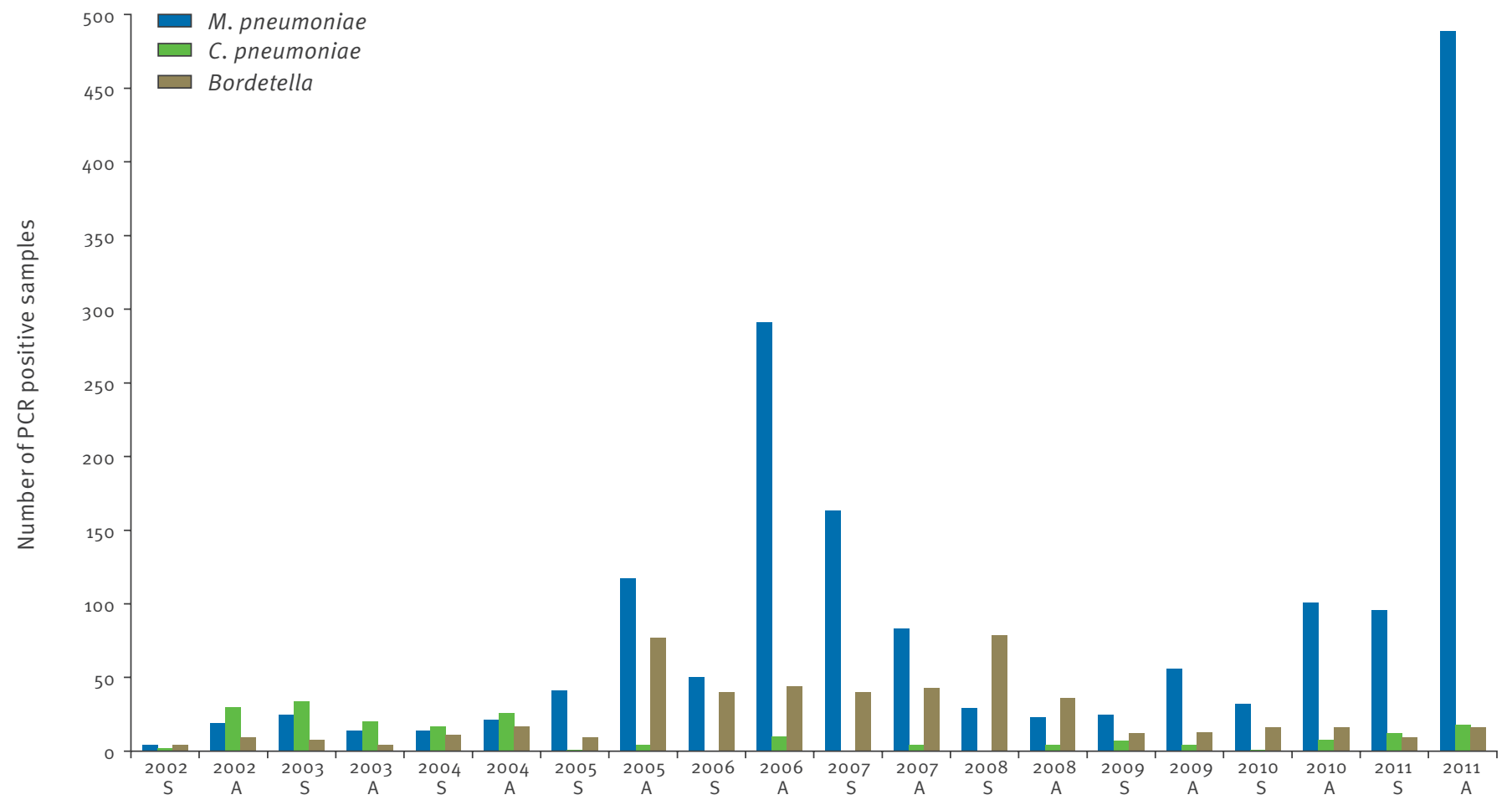

A: autumn; S: spring.

\section{FIGURE 3}

Prescriptions of penicillin V and macrolides/doxycycline per 1,000 inhabitants in Sweden, and monthly number of laboratory-confirmed diagnoses of Mycoplasma pneumoniae by PCR in Skövde, 2007-2011

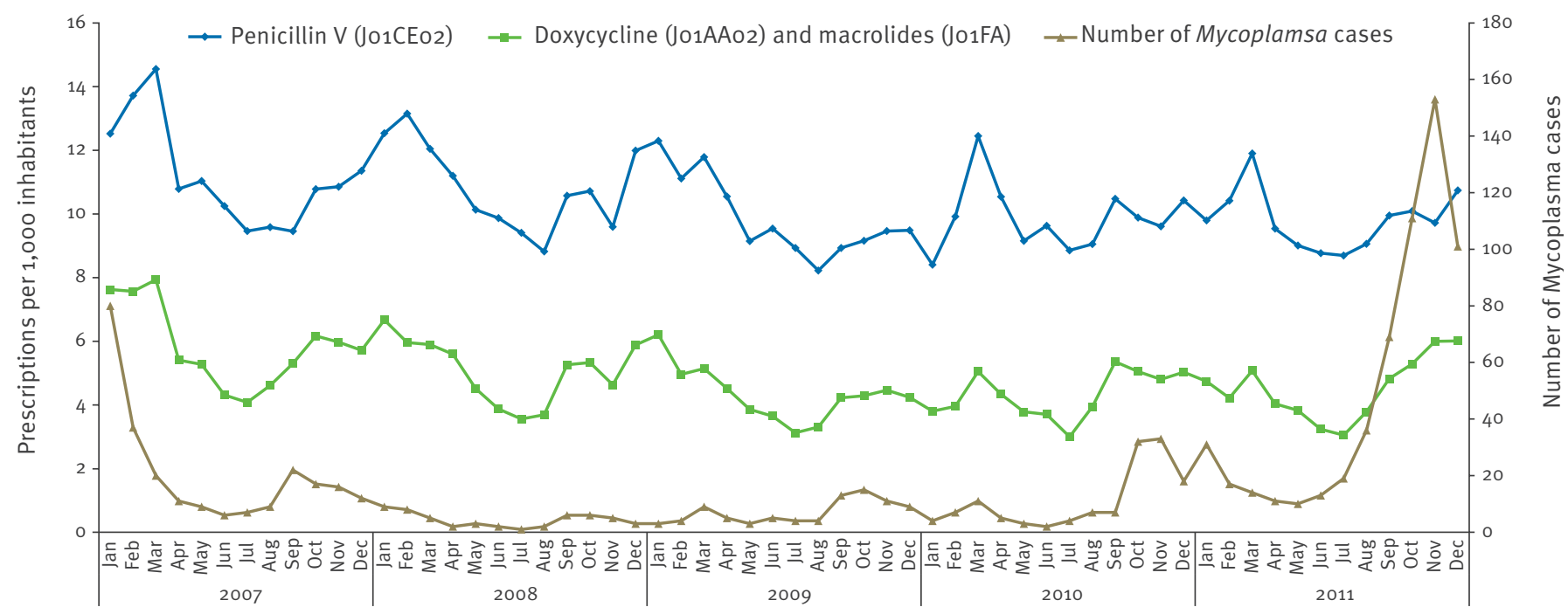


The high rate of $P C R$ positives (23\%) may indicate a more selective sampling than in the other countries, but also that PCR is a more efficient test. However, although the total number of positive PCR samples was smaller in 2006 , the rate of positive tests (23\%) was as high during the peak in 2006 as in 2011, indicating that the intensity of the two epidemics may have been similar. This underlines the value of knowing the catchment population and number of samples examined in epidemiological analyses.

Approximately $90 \%$ of all antibiotics in Sweden are prescribed for outpatients (data provided by Concise, Apoteket Service $A B$ ) and $60 \%$ of these for respiratory tract infections [15]. A main indication for choosing doxycycline and macrolides is atypical pneumonia. It is plausible that the selective increase in prescriptions of doxycycline and macrolides, but not of penicillin $\mathrm{V}$, in 2011 compared to 2009 could to a large extent be explained by variations in the incidence of Mycoplasma rather than the recurrent increase in lower respiratory tract infections seen every autumn. The prescriptions of doxycycline and macrolides in Sweden increased by $13 \%$ between October and November 2011, while the use of macrolides alone increased by approximately $125 \%$ in Norway during the same period [8]. Although the increase in prescriptions in Sweden was lower than in Norway, we believe that many patients with mild symptoms have been treated unnecessarily. To allow for rapid and correct guidance on the use of antibiotics at an early stage of epidemics of $M$. pneumoniae and possibly other causes of atypical pneumonia, structured laboratory reporting is desirable. A European consensus on indications for treatment should be sought, to limit the number of prescriptions for mild cases and thereby the antibiotic burden.

\section{References}

1. Mills GD, Oehley MR, Arrol B. Effectiveness of beta lactam antibiotics compared with antibiotics active against atypical pathogens in non-severe community acquired pneumonia: meta-analysis. BMJ. 2005;330(7489):456

2. Farmakologisk behandling av nedre luftvägsinfektioner i öppen vård. [Medical treatment of lower respiratory tract infections in primary care]. Information från Läkemedelsverket. 2008;3:7-17. Swedish. Available from: http://www.lakemedelsverket.se/ upload/om-lakemedelsverket/publikationer/information-franlakemedelsverket/Info_fr_LV_2008-3-rev.pdf

3. Lenglet A, Herrador Z, Magiorakos AP, Leitmeyer K, Coulombier D, European Working Group on Mycoplasma pneumoniae surveillance. Surveillance status and recent data for Mycoplasma pneumoniae infections in the European Union and European Economic Area, January 2012. Euro Surveill. 2012;17(5):pii=20075. Available from: http://www. eurosurveillance.org/ViewArticle.aspx?Articleld=20075

4. En ökning av antalet mycoplasmainfektioner i Sverige. [Increase in the number of Mycoplasma infections in Sweden]. EPI-aktuellt. 2010;9(49). Swedish. Available from: http://www.smittskyddsinstitutet.se/publikationer/ smis-nyhetsbrev/epi-aktuellt/epi-aktuellt-2010/ epi-aktuellt-vol-9-nr-49-9-december-2010-/

5. Mycoplasma aktuellt - igen. [Mycoplasma is news - again]. Stockholm: Smittskyddsinstitutet; Nov 2011. Swedish. Available from: http://www.smittskyddsinstitutet.se/ nyhetsarkiv/2011/mycoplasma-aktuellt--igen/

6. Fortsatt mycket mykoplasma i Sverige. [Still a lot of Mycoplasma in Sweden]. Stockholm: Smittskyddsinstitutet; Jan 2012. Swedish. Available from: http://www. smittskyddsinstitutet.se/nyhetsarkiv/2012/ fortsatt-mycket-mykoplasma-i-sverige

7. Polkowska A, Harjunpää, A, Toikkanen S, Lappalainen $M$, Vuento R, Vuorinen T, et al. Increased incidence of Mycoplasma pneumoniae in Finland, 2010-2011. Euro Surveill. 2012;17(5):pii=20072. Available from:

8. Blystad H, Ånestad G, Vestrheim DF, Madsen S, Rønning K. Increased incidence of Mycoplasma pneumoniae infections in Norway 2011. Euro. Surveill. 2012;17(5): pii=20074. Available from: http://www.eurosurveillance.org/ViewArticle. aspx?Articleld $=20074$

9. Uldum SA, Bangsborg JM, Gahrn-Hansen B, Ljung R, Mølvgaard C, Føns Petersen R, et al. Epidemic of Mycoplasama pneumoniae infection in Denmark, 2010 and 2111. Euro Surveill. 2012;17(5):pii=20073. Available from: http://www. eurosurveillance.org/ViewArticle.aspx?Articleld=20073

10. Hardegger D, Nadal D, Bossart W, Altwegg M, Dutly F. Rapid detection of Mycoplasma pneumoniae in clinical samples by real-time PCR. J Microbiol Methods. 2000;41(1):45-51.

11. Kuoppa Y, Boman J, Kumlin U, Eriksson I, Allard A. Quantitative detection of respiratory Chlamydia pneumoniae infection by real-time PCR. J Clin Microbiol. 2002;40(6):2273-4.

12. Templeton KE, Scheltinga SS, van der Zee A, Diederen BM, Kruijssen AM, Goossens $\mathrm{H}$, et al. Evaluation of real-time PCR for detection of and discrimination between Bordetella pertussis, Bordetella parapertussis, and Bordetella holmesii for clinical diagnosis. J Clin Microbiol. 2003;41(9):4121-6.

13. Waites KB, Talkington DF. Mycoplasma pneumoniae and its role as a human pathogen. Clin Microbiol Rev. 2004;17(4):697-728.

14. Claesson BE, Enroth H, Elowson S, Hellgren-Leonardsson M. Evaluation of diagnostic methods for Mycoplasma pneumoniae and Chlamydophila pneumoniae using serology, PCR and the BD ProbeTec ET System. 14th European Conference on Clinical Microbiology and Infectious Diseases (ECCMID). 2004 May 1-4; Prague, Czech Republic. Abstract no. O60. Clin Microbiol Infect. 2004; 10;Suppl s3:6-7.

15. Lundborg CS, Olsson E, Mölstad S, Swedish Study Group on Antibiotic Use. Antibiotic prescribing in outpatients: a 1-week diagnosis-prescribing study in 5 counties in Sweden. Scand J Infect Dis. 2002; 34(6):442-8. 